Provided for non-commercial research and education use. Not for reproduction, distribution or commercial use.

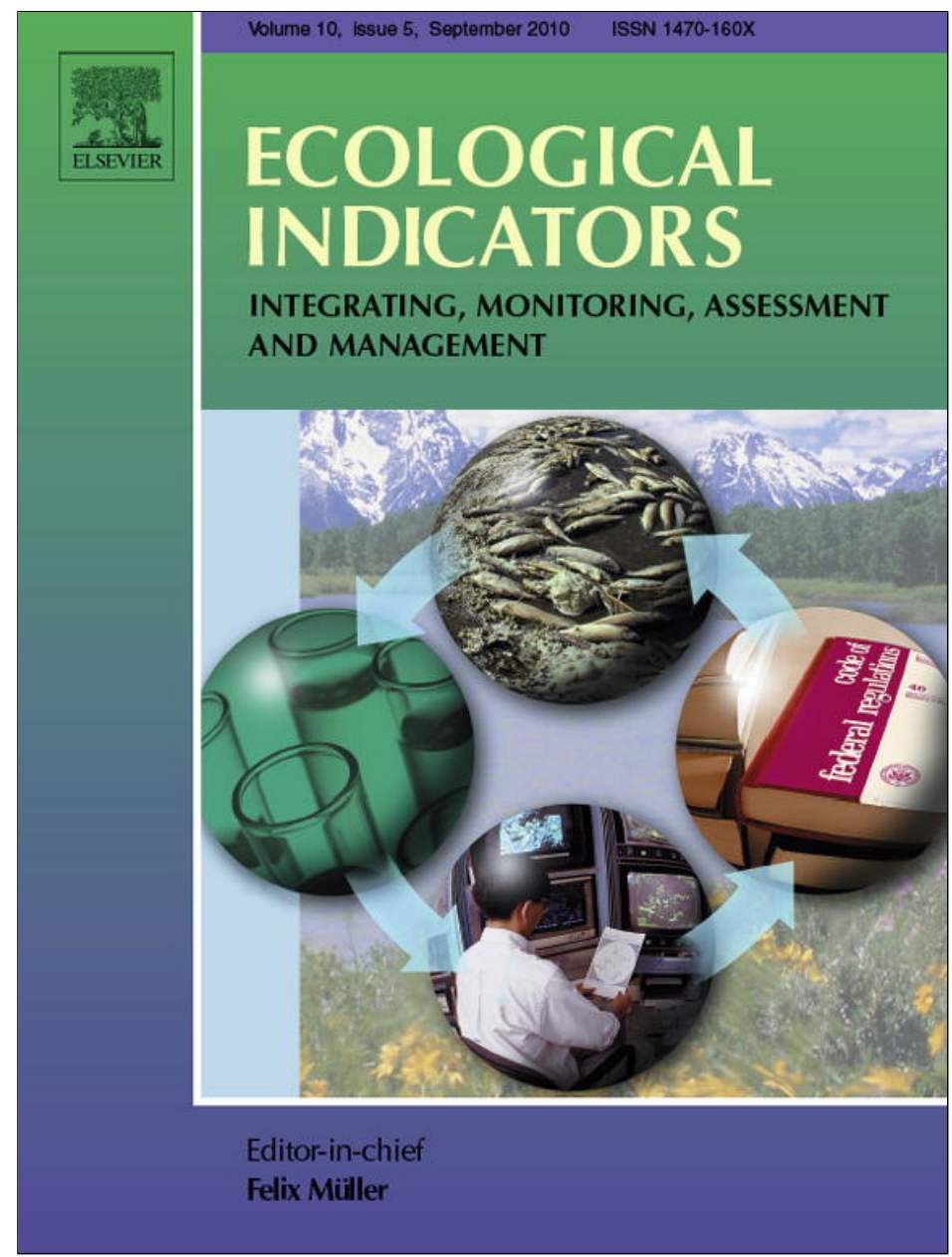

This article appeared in a journal published by Elsevier. The attached copy is furnished to the author for internal non-commercial research and education use, including for instruction at the authors institution and sharing with colleagues.

Other uses, including reproduction and distribution, or selling or licensing copies, or posting to personal, institutional or third party websites are prohibited.

In most cases authors are permitted to post their version of the article (e.g. in Word or Tex form) to their personal website or institutional repository. Authors requiring further information regarding Elsevier's archiving and manuscript policies are encouraged to visit:

http://www.elsevier.com/copyright 


\title{
Development of a macrophyte-based index of biotic integrity for Minnesota lakes
}

\author{
Marcus W. Beck ${ }^{\mathrm{a}, *}$, Lorin K. Hatch ${ }^{\mathrm{a}}$, Bruce Vondracek ${ }^{\mathrm{b}}$, Ray D. Valley ${ }^{\mathrm{c}}$ \\ a Conservation Biology Graduate Program, 187 McNeal Hall, 1985 Buford Avenue, St. Paul, MN 55108, USA \\ ${ }^{\mathrm{b}}$ US Geological Survey, Minnesota Cooperative Fish and Wildife Research Unit ${ }^{1}, 1980$ Folwell Ave, St. Paul, MN 55108, USA \\ c Minnesota Department of Natural Resources, Division of Fish and Wildlife, 1200 Warner Road, St. Paul, MN 55106, USA
}

\section{A R T I C L E I N F O}

\section{Article history:}

Received 22 November 2009

Received in revised form 7 February 2010

Accepted 14 February 2010

\section{Keywords:}

Aquatic macrophytes

Biological assessment

IBI

Lake monitoring

Metrics

Point intercept

\begin{abstract}
A B S T R A C T
Traditional approaches for managing aquatic resources have often failed to account for effects of anthropogenic disturbances on biota that are not directly reflected by chemical and physical proxies of environmental condition. The index of biotic integrity (IBI) is a potentially effective assessment method to integrate ecological, functional, and structural aspects of aquatic systems. A macrophyte-based IBI was developed for Minnesota lakes to assess the ability of aquatic plant communities to indicate environmental condition. The index was developed using quantitative point intercept vegetation surveys for 97 lakes that represent a range of limnological and watershed characteristics. We followed an approach similar to that used in Wisconsin to develop the aquatic macrophyte community index (AMCI). Regional adaptation of the AMCI required the identification of species representative of macrophyte communities in Minnesota. Metrics and scaling methods were also substantially modified to produce a more empirically robust index. Regression analyses indicated that IBI scores reflected statewide differences in lake trophic state $\left(R^{2}=0.57, F=130.3, \mathrm{df}=1,95, p<0.005\right)$, agricultural $\left(R^{2}=0.51, F=83.0, \mathrm{df}=1,79, p<0.005\right)$, urban $\left(R^{2}=0.22, F=23.0, \mathrm{df}=1,79, p<0.005\right)$, and forested land uses $\left(R^{2}=0.51, F=84.7, \mathrm{df}=1,79, p<0.005\right)$, and county population density $\left(R^{2}=0.14, F=16.6, \mathrm{df}=1,95, p<0.005\right)$. Variance partitioning analyses using multiple regression models indicated a unique response of the IBI to human-induced stress separate from a response to natural lake characteristics. The IBI was minimally affected by differences in sample point density as indicated by Monte Carlo analyses of reduced sampling effort. Our analysis indicates that a macrophyte IBI calibrated for Minnesota lakes could be useful for identifying differences in environmental condition attributed to human-induced stress gradients.
\end{abstract}

() 2010 Elsevier Ltd. All rights reserved.

\section{Introduction}

The development of reliable methods to restore and maintain the chemical, physical, and biological integrity of surface waters has been a primary objective of resource managers since the passage of the 1972 Clean Water Act (CWA) by the United States Congress (33USC1251). The inability of traditional chemical and effluent-based standards to fulfill requirements of the CWA established a need for environmental agencies to develop timely and effective biological assessment (bioassessment) meth-

\footnotetext{
* Corresponding author at: 200 Hodson Hall, 1980 Folwell Ave, St. Paul, MN 55108 USA. Tel.: +1 6126252294; fax: +1 6126255299.

E-mail addresses: beckx266@umn.edu (M.W. Beck), Lorin.Hatch@hdrinc.com (L.K. Hatch), bvondrac@umn.edu (B. Vondracek), Ray.Valley@dnr.state.mn.us (R.D. Valley).

1 The Unit is sponsored by the US Geological Survey, the University of Minnesota the Minnesota Department of Natural Resources, the US Fish and Wildlife Service, and the Wildlife Management Institute.
}

ods. Initially proposed in the 1980s for stream bioassessment, an index of biotic integrity (IBI) for fish was designed to integrate ecological, functional, and structural aspects of aquatic systems and is considered sufficient for fulfilling the biological integrity requirement of the CWA (Karr, 1981, 1991; Fausch et al., 1984). Successful applications in streams and flexibility of the original framework have prompted researchers to examine applicability of the IBI for ecological assessment of lakes (see Beck and Hatch, 2009).

Different biological communities have been proposed for the development of lake IBIs including fish (Minns et al., 1994; Jennings et al., 1999; McDonough and Hickman, 1999; Thoma, 1999; Whittier, 1999; Drake and Pereira, 2002; Drake and Valley, 2005), macroinvertebrates (Lewis et al., 2001; Blocksom et al., 2002), and plankton (Kane et al., 2009). In addition, macrophytebased IBIs have received attention (Nichols et al., 2000; Rothrock et al., 2008) as aquatic plants offer several advantages for bioassessment including immobility, ease of identification, ease of sampling, and relationships with lake fisheries (Clayton and Edwards, 2006; 
Cross and McInerny, 2006; Beck and Hatch, 2009). Aquatic plants also respond to environmental changes within ecologically relevant timeframes, which may provide early warning indications of system resilience that inhibits regime shifts (Scheffer et al., 1998; Genkai-Cato and Carpenter, 2005; Valley and Drake, 2007). Alternatively, an aquatic plant IBI could be a useful tool for monitoring restoration efforts as seed banks retained in sediment are a viable source for species recolonization that respond to environmental condition (Jurik et al., 1994).

Several macrophyte-based IBIs developed in recent years have particular importance for the management of temperate lakes. Nichols et al. (2000) described the aquatic macrophyte community index (AMCI) developed for Wisconsin as a multipurpose, multimetric tool for assessing the biological quality of aquatic plant communities. Seven metrics derived from transect data established the foundation of the AMCI: maximum depth of plant growth; percentage of the littoral area vegetated; Simpson's diversity index; relative frequency of submersed, exotic, and sensitive species; and taxa richness. However, metrics were chosen a priori based on hypothesized relationships to disturbance. As such, the metric selection process lacked rigorous statistical evaluation and an interpretation of the influence of each metric on the index was not conducted. Regardless, AMCI scores indicated significant differences in water quality trends related to humaninduced stress affecting lake productivity among Wisconsin ecoregions.

More recently, Rothrock et al. (2008) developed a plant index of biotic integrity (PIBI) to assess ecological condition of littoral areas of Indiana lakes. Metrics and PIBI scores were examined against measures of habitat quality, land use, and management categories that described the degree of anthropogenic influence on a lake (e.g., recreational, industrial, restoration, etc.). PIBI scores responded to a gradient of human-induced stress indicated by explanatory variables. However, a primary disadvantage of the approach used by Rothrock et al. (2008) was reliance on qualitative data that may not be as robust as more quantitative approaches to index development. For example, Rothrock et al. (2008) described the PIBI sampling method as a qualitative, non-exhaustive census to rapidly assess biological diversity and relative abundance of macrophyte communities. Furthermore, PIBI scores were evaluated against best professional judgment rankings of site condition and a modified qualitative habitat evaluation index. The development of an index that produces repeatable results may require more quantitative methods for verifying metric and index response to human-induced stress.

In Minnesota, aquatic resource managers have realized the need for developing biological indicators that can signal problems in water quality and fish habitat before regime shift thresholds are crossed (Scheffer et al., 1998; Valley and Drake, 2007). Our goal was to develop a macrophyte-based IBI to examine the ability of aquatic plants to discriminate between lakes of differing environmental condition in Minnesota. Our objectives were to (1) utilize spatially explicit point intercept vegetation surveys that provided quantitative information of macrophyte coverage, (2) provide an empirical interpretation of metric and IBI response to hypothesized explanatory variables representing anthropogenic and natural lake characteristics, and (3) evaluate index sensitivity to individual metrics and sampling effort. The AMCI developed in Wisconsin provided a conceptual basis for index development (Nichols et al., 2000). However, our approach provides an empirical examination of IBI response to statewide gradients of lake characteristics, which may not be apparent using a regional approach (Moyle, 1945, 1956). Validation of a macrophyte IBI will provide managers with a framework to address impacts on Minnesota lakes, with potential implications for the management of temperate lakes in other midwestern states.

\section{Methods}

\subsection{Data sources}

Lakes were chosen that included the same lake classes (Schupp, 1992) used to develop the Minnesota fish-based lake IBI (Drake and Pereira, 2002; Drake and Valley, 2005) to facilitate use of both indices for lake monitoring. The Minnesota Department of Natural Resources (DNR) lake classification scheme (Schupp, 1992) established 44 different lake classes based on combinations of nine limnological and morphometric characteristics that explain $78.7 \%$ of the variance among lakes: surface area, volume, area:shoreline ratio, maximum depth, percent littoral surface area, secchi transparency, total alkalinity, shoreline development index (Wetzel, 2001), and growing season length. Nineteen lake classes were represented in the dataset, with $63 \%$ of lakes from five classes. As such, lakes represented in the dataset captured several statewide gradients of natural lake characteristics. Lakes were located in the North Central Hardwood Forests (NCHF, $n=43$ ), Northern Glaciated Plains (NGP, $n=6$ ), Northern Lakes and Forests (NLF, $n=38$ ), and Western Cornbelt Plains (WCP, $n=10$ ) level III ecoregions (Omernik, 1987) (Fig. 1).

The dataset for IBI development $(n=97)$ was compiled from point intercept surveys conducted by the Minnesota DNR. The point intercept method establishes a grid of sampling points in the littoral zone and provides quantitative, spatially explicit data that offer more areal coverage than traditional transect methods (Madsen, 1999; Cheruvelil and Soranno, 2008). A double-sided rake was used at each sampling point to gather species presence/absence information. Depth at each sample site was recorded using a survey rod. A minimum of 0.7 points per littoral acre was considered adequate for capturing $80 \%$ of total species richness (C. Tomcko and R.D. Valley, unpublished data). Additionally, three lakes (Christmas, Jane, and Square) were sampled at approximately 3.25 points per littoral acre to examine the effect of sampling effort on IBI scores. Mean sampling density for lakes in the development dataset was 0.94 points per littoral acre, corresponding to approximately $85 \%$ of total species richness. Surveys were conducted from 2001 to 2008 ,

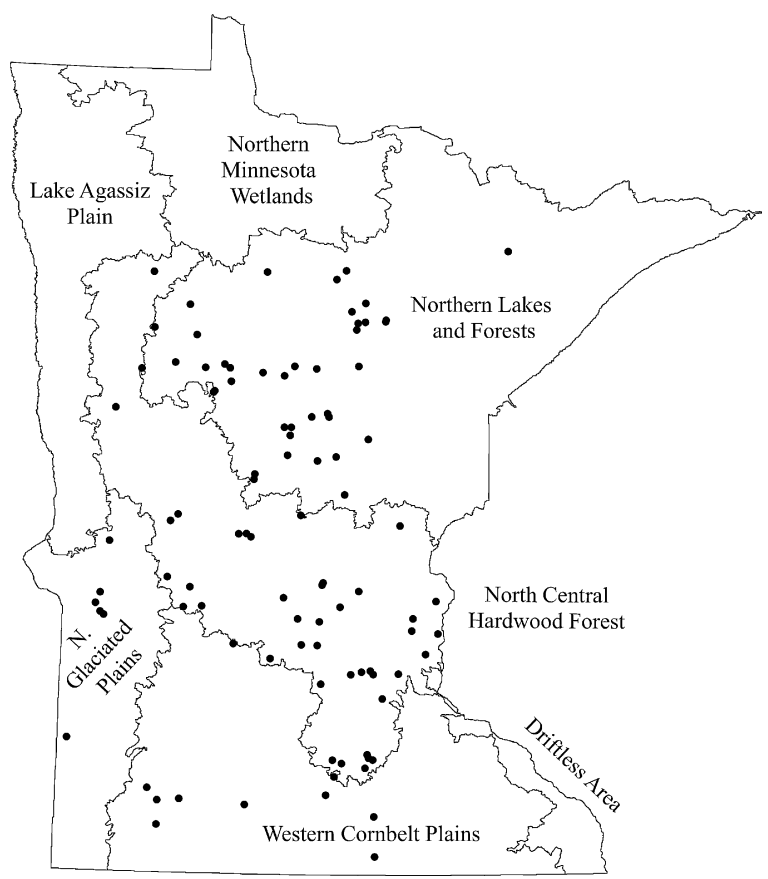

Fig. 1. Location of lakes used for IBI development. Level III ecoregion borders are indicated (Omernik, 1987). 
Table 1

Species list, $C$ values, tolerance classifications ( $C<3$ tolerant, $C>7$ intolerant, $C=0$ introduced), and submersed species used to develop TOLR, SENS, and SUBM metrics (edited for brevity). $C$ values are described in Milburn et al. (2007). $\mathrm{T}=$ tolerant, $\mathrm{I}=$ intolerant/sensitive, and $\mathrm{S}=$ submersed.

\begin{tabular}{|c|c|c|c|c|}
\hline Scientific name & Common name & $C$ value & Tolerance & Submersed \\
\hline Acorus calamus & Sweet Flag & 0 & $\mathrm{~T}$ & \\
\hline Bidens beckii & Water Marigold & 8 & I & $S$ \\
\hline Butomus umbellatus & Flowering Rush & 0 & $\mathrm{~T}$ & \\
\hline Ceratophyllum demersum & Coontail & 2 & $\mathrm{~T}$ & $\mathrm{~S}$ \\
\hline Cyperus esculentus & Chufa Sedge & 0 & $\mathrm{~T}$ & \\
\hline Elodea canadensis & Canada Waterweed & 4 & & S \\
\hline Heteranthera dubia & Water Stargrass & 6 & & S \\
\hline Hippuris vulgaris & Marestail & 9 & I & $S$ \\
\hline Iris pseudacorus & Yellow Flag Iris & 0 & $\mathrm{~T}$ & \\
\hline Isoetes spp. ${ }^{\mathrm{a}}$ & Quillwort spp. & - & I & S \\
\hline Lythrum salicaria & Purple Loosestrife & 0 & $\mathrm{~T}$ & \\
\hline Myriophyllum sibiricum & Northern Water Milfoil & 7 & & S \\
\hline Myriophyllum spicatum & Eurasian Water Milfoil & 0 & $\mathrm{~T}$ & $S$ \\
\hline Najas flexilis & Bushy Pondweed & 5 & & S \\
\hline Najas gracillima & Northern Naiad & 10 & I & S \\
\hline Najas guadalupensis & Southern Naiad & 8 & I & S \\
\hline Najas marina & Spiny Naiad & 4 & & S \\
\hline Nelumbo lutea & Yellow Lotus & 8 & I & \\
\hline Phalaris arundinacea & Reed Canary Grass & 0 & $\mathrm{~T}$ & \\
\hline Potamogeton amplifolius & Large-leaf pondweed & 7 & & $S$ \\
\hline Potamogeton crispus & Curly-leaf Pondweed & 0 & $\mathrm{~T}$ & S \\
\hline Potamogeton filiformis & Thread-leaf pondweed & 8 & $\mathrm{I}$ & S \\
\hline Potamogeton foliosus & Leafy Pondweed & 6 & & $\mathrm{~S}$ \\
\hline Potamogeton friesii & Fries Pondweed & 8 & I & S \\
\hline Potamogeton gramineus & Variable-leaf pondweed & 7 & & S \\
\hline Potamogeton illinoensis & Illinois Pondweed & 6 & & S \\
\hline Potamogeton natans & Floating-leaf Pondweed & 5 & & S \\
\hline Potamogeton nodosus & River Pondweed & 6 & & $S$ \\
\hline Potamogeton pectinatus & Sago Pondweed & 3 & & $S$ \\
\hline Potamogeton praelongus & White-stem Pondweed & 7 & & S \\
\hline Potamogeton pusillus & Small Pondweed & 7 & & S \\
\hline Potamogeton richardsonii & Claspingleaf Pondweed & 5 & & $S$ \\
\hline Potamogeton robbinsii & Fern Pondweed & 8 & I & $\mathrm{S}$ \\
\hline Potamogeton zosteriformis & Flat-stem Pondweed & 6 & & $\mathrm{~S}$ \\
\hline Ranunculus spp. ${ }^{\mathrm{b}}$ & Buttercup spp. & - & & S \\
\hline Rumex maritimus & Golden Dock & 1 & $\mathrm{~T}$ & \\
\hline Sagittaria cristata & Arrowhead & 8 & I & \\
\hline Typha angustifolia & Narrow-leaved Cattail & 0 & $\mathrm{~T}$ & \\
\hline Typha latifolia & Broad-leaved Cattail & 2 & $\mathrm{~T}$ & \\
\hline Utricularia cornuta & Horned Bladderwort & 10 & I & S \\
\hline Utricularia gibba & Humped Bladderwort & 9 & I & S \\
\hline Utricularia intermedia & Flat-leaf Bladderwort & 8 & I & S \\
\hline Utricularia minor & Bladderwort & 8 & I & S \\
\hline Utricularia purpurea & Purple-flower Bladderwort & 10 & I & S \\
\hline Utricularia resupinata & Lavender-flower Bladderwort & 10 & I & $\mathrm{S}$ \\
\hline Vallisneria americana & Wild Celery & 6 & & $\mathrm{~S}$ \\
\hline Zizania spp. & Wild Rice & 8 & I & \\
\hline
\end{tabular}

a All $C$ values greater than 7 .

b All $C$ values less than 8 and greater than 2 .

with the earliest seasonal survey on 2 June 2003 and the latest on 24 September 2002. Surveys were conducted in all months of the growing season with 32\% in June, 29\% in July, 33\% in August, and 6\% in September. Two lakes devoid of vegetation were removed from the dataset.

\subsection{Adaptation and modification of the AMCI}

Three metrics that assess the relative frequency of different species required the identification of sensitive, tolerant, and submersed species (SENS, TOLR, and SUBM metrics, respectively) for regional adaptation of the AMCI to Minnesota lakes (Table 1 ). A catalog of Minnesota aquatic plants enabled identification of species used for these three metrics (Milburn et al., 2007). Coefficients of conservatism ( $C$ values) were used as indications of species tolerance to human-induced stress. The $C$ value is the estimated probability that a plant is likely to occur in a lake believed to be relatively unaltered from pre-settlement conditions (Nichols, 1999). Sensitive species were defined as having $C$ values greater than 7 , whereas tolerant species were defined as having $C$ values less than 3. Introduced species were also considered tolerant ( $C$ value of 0 ). Submersed species were generally defined as rooted in sediment with the majority of foliage beneath the water surface (Lacoul and Freedman, 2006). Relative frequency was calculated as the proportion of individual species frequencies for a given metric (e.g., species frequencies for sensitive macrophytes) to the summation of all species frequencies. Individual species frequencies were calculated as the number of points with a species divided by all points containing plants.

Several AMCI metrics were structurally modified to produce a robust index (Table 2). Maximum depth of plant growth (MAXD) was defined by Nichols et al. (2000) as the deepest sampling point with vegetation. However, in Minnesota, vagrant sprigs of vegetation can occur well beyond the depth of most vegetation growth and may not be detected in repeated surveys (M. Beck, personal observation). Accordingly, the metric was modified to equal depth where $95 \%$ of plant growth occurred within the basin. The percentage of littoral zone vegetated metric (LITT) used the modified maximum 
Table 2

Metric abbreviations, descriptions, means ( $\pm 95 \%$ confidence intervals), and ranges $(n=97)$.

\begin{tabular}{|c|c|c|c|}
\hline Metric & Description & Mean & Range \\
\hline MAXD & Maximum depth of plant growth, 95\% occurrence (m) & $3.2(2.9-3.5)$ & $0.5-7.9$ \\
\hline LITT & Percentage of littoral vegetated & $0.80(0.75-0.85)$ & $0-1$ \\
\hline OVER & Number of species with relative frequency over $10 \%$ & $5.7(4.9-6.4)$ & $0-17$ \\
\hline SUBM $^{\mathrm{a}}$ & Relative frequency of submersed species & $0.35(0.32-0.38)$ & $0-0.59$ \\
\hline SENS & Relative frequency of sensitive species & $0.05(0.03-0.07)$ & $0-0.59$ \\
\hline TOLR & Relative frequency of tolerant species & $0.23(0.18-0.27)$ & $0-0.94$ \\
\hline TAXA & Number of native taxa & $16.1(14.2-18.1)$ & $1-36$ \\
\hline
\end{tabular}

a Values represent transformed metric $(\lambda=6.04)$.

depth of plant growth as the limit of littoral zone growth. The relative frequency of exotic species metric was modified to include tolerant species to represent the relative contribution of major plant species (e.g., Ceratophyllum demersum) that may indicate conditions characterized by homogeneous species composition. The Simpson's diversity index metric was replaced with a metric that quantified the number of species with relative frequency over $10 \%$ (OVER). Although Simpson's diversity offers a useful measure of community composition, inclusion of an index within a larger index may complicate the interpretation and communication of information obtained from IBI scores. The modified metric provides an easily interpretable surrogate measure of diversity that implicitly incorporates richness and evenness. Finally, number of native taxa (TAXA) replaced the original species richness metric that included introduced species. Introduced species were identified from Milburn et al. (2007) and removed from total species richness for each lake.

\subsection{Human-induced stress variables and lake characteristics}

Landscape-level measures of human-induced stress (anthropogenic variables) were quantified for each lake using ArcGIS version 9.2 (ESRI, 2006) (Table 3). Carlson trophic state index (TSI) (Carlson, 1977), percent cover of land use type in the watershed, and population density of the county in which a lake was located (people $/ \mathrm{km}^{2}$ ) were anthropogenic variables because of documented impacts on water quality (Roth et al., 1996; Egertson et al., 2004; Danz et al., 2007). TSI provides a measure of lake productivity by incorporating measures of water clarity (Secchi disk measurements), total phosphorus (TP), and chlorophyll $a$ (chl a). TSI values were calculated using equations in Carlson (1977) and lake water quality data obtained from the Minnesota Pollution Control Agency (PCA) (MNPCA, 2009). Percent cover for the three land use variables were quantified for the immediate catchment and all catchments upstream contributing surficial water to each lake (defined as the watershed) (MNDNR, 2009). Land use was obtained from 2001 National Land Cover Data (USGS, 2009) and quantified for 81 lakes. Land use data could not be quantified without watershed delineations, which were unavailable for 16 lakes. County population densities were obtained from statewide census data (MNDOA, 2000). Landscape-level anthropogenic variables represent stressors that primarily affect lake productivity. As such, linear regression analyses indicated agricultural and urban land use were positively related to TSI $\left(R^{2}=0.28, F=31.6, \mathrm{df}=1\right.$, $79, p<0.005 ; R^{2}=0.11, F=10.8, \mathrm{df}=1,79, p<0.005$, respectively), whereas forested land use was negatively related to TSI $\left(R^{2}=0.25\right.$, $F=28.2, \mathrm{df}=1,79, p<0.005)$. Similarly, population density was highly correlated with urban land use in the watershed $\left(R^{2}=0.28\right.$, $F=32.2, \mathrm{df}=1,79, p<0.005$ ).

Natural lake characteristics (natural variables) that affect biological community composition (Schupp, 1992) were quantified in a GIS (ESRI, 2006) using data compiled from state agency databases (MNDNR, 2009; MNPCA, 2009). Variables included surface area (hectares), maximum depth $(\mathrm{m})$, total alkalinity $\left(\mathrm{mg} / \mathrm{L} \mathrm{CaCO}_{3}\right)$, percent littoral surface area, shoreline development index (SDI), and mean July temperature (Table 3 ). Data were available for most lakes; however, alkalinity was available for only 63 lakes. Percent littoral was defined as the proportion of lake surface area where depth was less than $4.5 \mathrm{~m}$. SDI was defined as the ratio of the length of shoreline to the circumference of a circle with an area equal to that of the lake (Wetzel, 2001) and is an indication of shoreline complexity. Mean July temperature was used to examine regional climate effects on macrophyte communities. Temperatures were obtained from GIS shapefiles describing statewide climate data from 1961 to 1990 (MNDNR, 2009). Spatial interpolation via kriging (Burrough and McDonnell, 1998; ESRI, 2006) was used to predict mean temperatures for each lake in the dataset.

\subsection{Examination of metrics}

All analyses were conducted with $R$ statistical software version 2.9.0 $(\alpha=0.05)$ (RDCT, 2009). Population density, agricultural, and urban land use exhibited substantial deviations from normality and were transformed prior to analysis using the Box-Cox method in

Table 3

Anthropogenic and natural characteristics describing study lakes $(n=97)$. Variables are not transformed. Anthropogenic variables represent watershed characteristics or within-lake characteristics affected by watershed activities. Natural variables were identified from Schupp (1992) lake classifications. 95\% confidence intervals are given in parentheses. TSI = trophic state index (Carlson, 1977), SDI = shoreline development index (Wetzel, 2001).

\begin{tabular}{|c|c|c|c|c|}
\hline Variable type & Variable & $N$ & Mean & Range \\
\hline \multirow[t]{5}{*}{ Anthropogenic } & TSI & 97 & $55.7(53.1-58.3)$ & 31.9-93.1 \\
\hline & Population density (people $/ \mathrm{km}^{2}$ ) & 97 & $48.6(23.3-73.9)$ & $3.0-710.7$ \\
\hline & Agricultural land use (\%) & 81 & $17.5(12.4-22.5)$ & $0-87.6$ \\
\hline & Urban land use (\%) & 81 & $20.7(13.9-27.5)$ & $0-99.0$ \\
\hline & Forested land use (\%) & 81 & $46.3(37.4-55.1)$ & $0-99.8$ \\
\hline \multirow[t]{6}{*}{ Natural } & Alkalinity $\left(\mathrm{mg} / \mathrm{L} \mathrm{CaCO}_{3}\right)$ & 63 & $130.6(119.4-141.8)$ & $15.0-310.0$ \\
\hline & Area (acres) & 97 & $537.2(416.9-657.5)$ & $45.3-4094.1$ \\
\hline & Littoral surface area (\%) & 91 & $66.1(60.4-71.7)$ & $14.4-100.0$ \\
\hline & Maximum depth (m) & 97 & $10.6(8.7-12.6)$ & $1.2-49.7$ \\
\hline & SDI & 96 & $1.82(1.69-1.94)$ & $1.03-3.83$ \\
\hline & Temperature $\left({ }^{\circ} \mathrm{C}\right)$ & 97 & $21.1(20.9-21.3)$ & $18.3-22.8$ \\
\hline
\end{tabular}


the following equation:

$y^{\lambda}=\frac{y^{\lambda-1}}{\lambda(G M(y))^{\lambda-1}}$

where $y^{\lambda}$ is the transformed variable, $G M(y)$ is the geometric mean of the non-transformed variable, and $\lambda$ is the maximum likelihood estimate of the transformation parameter $(\lambda=-0.48,-4.79$, and -5.27 for population density, agricultural, and urban land use, respectively) (Cook and Weisberg, 1999). Additionally, SUBM was transformed $(\lambda=6.04)$ as initial analyses indicated metric behavior could be improved with transformation. Raw (unscaled) metrics were examined for redundancy using Pearson's correlation coefficients to ensure metrics provided unique information. Two metrics were considered highly correlated if the correlation coefficient exceeded \pm 0.8 (Drake and Pereira, 2002). Pearson's correlation coefficients $(\alpha=0.05)$ were used to examine metric responses to anthropogenic and natural variables. Metrics were considered robust indicators of environmental condition based on predictable relationships with anthropogenic variables independent of a response that may co-vary with natural variables (Allan, 2004).

All non-redundant metrics correlated with at least one anthropogenic variable were retained for standardization to a common scale. Continuous variable metric scaling (Minns et al., 1994) was used instead of the discrete method proposed for AMCI metrics. Continuous metric scaling allows for a greater range of scores, avoids sequence gaps, and minimizes bias from Type I error (Fore et al., 1994). Raw metric scores were assigned a minimum value of zero and a maximum value of 10 , using the following equation and conditions (Minns et al., 1994):

$M_{S}=A+B \times M_{r}$

If $M_{r}<M_{\min }$, then $M_{s}=0$,

if $M_{r}>M_{\max }$, then $M_{s}=10$.

The standardized metric $\left(M_{S}\right)$ was calculated from the raw metric $\left(M_{r}\right)$ using a linear function with intercept $(A)$ and slope $(B) . M_{\min }$ and $M_{\max }$ define thresholds for values of $M_{S}$. For metrics positively related to biotic integrity, $M_{\min }$ was equal to the minimum value of $M_{r}$ and $M_{\max }$ was equal to the 95th percentile value of $M_{r}$. For metrics negatively related to biotic integrity, $M_{\min }$ was equal to the maximum value of $M_{r}$ and $M_{\max }$ was equal to the 5 th percentile value of $M_{r}$.

\subsection{IBI evaluation}

Total IBI scores were obtained from the summation of standardized metric scores for each lake and then converted to a 0-100 scale by multiplying the sum by $10 / N_{m}$, where $N_{m}$ is the number of metrics (Minns et al., 1994). Total IBI scores were compared to anthropogenic and natural variables (Section 2.3) using linear regression models ( $\alpha=0.05)$ (RDCT, 2009).

The relative contribution of environmental and anthropogenic variables to IBI scores was examined using a variance partitioning analysis that examined coefficients of determination from different regression models (Legendre and Legendre, 1998; Irz et al., 2008). Three multiple regression models (MLR) were developed to explain IBI scores using anthropogenic variables, natural variables, and combined variables $(\alpha=0.05)$ (RDCT, 2009). Principal component analyses were conducted prior to the development of MLR models to reduce data dimensionality and remove collinearity among explanatory variables. Principal component axes were extracted from correlation matrices (McCune and Grace, 2002; RDCT, 2009) for anthropogenic (Ant1 and Ant2), natural (Nat1, Nat2, and Nat3), and combined variables (All1, All2, All3, and All4). The component axes included in each regression model explained at least $75 \%$ of the cumulative proportion of variance among the separate explanatory variables. MLR models were developed from each group of principal component axes and then evaluated using Akaike's information criterion (AIC) likelihood estimates in a backward stepwise algorithm for parameter selection (Akaike, 1973). The summation of $R^{2}$ values for the separate natural and anthropogenic MLR models minus the $R^{2}$ value from the combined model provided an indication of relative importance of each variable type, as well as which model(s) better described the relationship of variables to index scores. A negative value implies that the combined MLR model better explained the variation in scores than the separate MLR models (Legendre and Legendre, 1998).

A comparison of the IBI between ecoregions examined geographic differences in index scores. Mean IBI scores for each ecoregion were compared using standard methods for analysis of variance (ANOVA), followed by a post hoc Tukey multiple comparison test to identify individual ecoregion differences $(\alpha=0.05)$ (RDCT, 2009). Lakes in the NGP and WCP ecoregions were combined for analysis due to small sample sizes. Both ecoregions had similar land use practices.

\subsection{IBI sensitivity and effects of sampling effort}

A sensitivity analysis to examine the relative contribution of each metric to overall IBI scores was conducted for the entire dataset and for each ecoregion (Minns et al., 1994). Sensitivity of the IBI to each metric was calculated as the variance of the differences between the original IBI scores and recalculated IBI scores after metric removal. A higher variance suggested that the IBI was sensitive to a particular metric. The ratio of the variance of the differences within each ecoregion to the total variance indicated IBI sensitivity on an ecoregional basis. Metrics with ratios greater than the median for all metrics were considered potentially informative.

Christmas, Jane, and Square lakes located in the NCHF ecoregion were sampled at 3.14, 3.28, and 3.28 points per littoral acre, respectively, to evaluate the effects of sampling effort on IBI score. These lakes were chosen for analysis because they contain diverse plant communities, thereby increasing statistical power of the analysis. Christmas and Jane lakes were sampled during the summer of 2008, and Square Lake was sampled during the summer of 2006. Monte Carlo simulations were used to calculate IBI scores at $10 \%$ increments of sampling effort from $90 \%$ to $10 \%$ effort (RDCT, 2009). Using a stratified-random approach to prevent the elimination of large areas of a sampling grid, each lake was separated into four regions of approximate equal area for selection of sample points. For each level of sampling effort, survey points were randomly selected using 500 iterations. A mean IBI score and 95\% confidence interval was calculated for each level of sampling effort. A one-way $t$-test of means $(\alpha=0.05)$ was used to determine significant differences of IBI scores at $10 \%$ and $90 \%$ sampling effort for each lake (RDCT, 2009). Lastly, an examination of the relationship between species richness and sampling effort using rarefaction curves (Gotelli and Colwell, 2001) evaluated IBI response to changes in sampling effort.

\section{Results}

\subsection{Metric response}

No correlation coefficients between metrics exceeded \pm 0.8 , thus each metric contributed unique information to the IBI. However, OVER and TAXA exhibited the highest positive correlation ( $\rho=0.62$, $\mathrm{df}=95, p<0.005)$. TOLR and TAXA exhibited the highest negative correlation $(\rho=-0.28, \mathrm{df}=95, p<0.05)$.

All metrics were significantly correlated with at least one anthropogenic variable (Table 4a). Metrics positively related to 
Table 4a

Pearson's correlation coefficients between the seven IBI metrics and anthropogenic variables. $\alpha=0.05$; ns = not significant; TSI = trophic state index (Carlson, 1977).

\begin{tabular}{lccccr}
\hline Metric & TSI & People $/ \mathrm{km}^{2}$ & Ag & Urban & Forest \\
\hline MAXD & $-0.69^{* *}$ & $-0.08^{\text {ns }}$ & $-0.40^{* *}$ & $-0.08^{\text {ns }}$ & $0.23^{*}$ \\
LITT & $-0.58^{* *}$ & $-0.12^{\text {ns }}$ & $-0.47^{* *}$ & $-0.17^{\text {ns }}$ & $0.37^{* *}$ \\
OVER & $-0.62^{* *}$ & $-0.18^{\text {ns }}$ & $-0.53^{* *}$ & $-0.36^{* *}$ & $0.55^{* *}$ \\
SUBM & $0.00^{\text {ns }}$ & $0.18^{\text {ns }}$ & $0.21^{\text {ns }}$ & $0.23^{*}$ & $-0.28^{*}$ \\
SENS & $-0.23^{*}$ & $-0.19^{\text {ns }}$ & $-0.42^{* *}$ & $-0.29^{*}$ & $0.40^{* *}$ \\
TOLR & $0.18^{\text {ns }}$ & $0.45^{* *}$ & $0.26^{*}$ & $0.32^{* *}$ & $-0.43^{* *}$ \\
TAXA & $-0.71^{* *}$ & $-0.34^{* *}$ & $-0.58^{* *}$ & $-0.43^{* *}$ & $0.61^{* *}$ \\
\hline
\end{tabular}

${ }^{*} p<0.05$.

*** $p<0.005$.

\section{Table 4b}

Pearson's correlation coefficients between the seven IBI metrics and natural variables. $\alpha=0.05$; ns = not significant; SDI = shoreline development index (Wetzel, 2001).

\begin{tabular}{lrlllll}
\hline Metric & Area & $\begin{array}{l}\text { Maximum } \\
\text { depth }\end{array}$ & Alkalinity & \% Littoral & SDI & Temperature \\
\hline MAXD & $0.11^{\text {ns }}$ & $0.50^{* *}$ & $-0.16^{\text {ns }}$ & $-0.32^{* *}$ & $0.13^{\text {ns }}-0.28^{*}$ \\
LITT & $0.02^{\text {ns }}$ & $0.27^{*}$ & $-0.22^{\text {ns }}$ & $-0.02^{\text {ns }}$ & $0.02^{\text {ns }}-0.29^{* *}$ \\
OVER & $-0.08^{\text {ns }}$ & $0.35^{* *}$ & $-0.15^{\text {ns }}$ & $-0.17^{\text {ns }}$ & $0.11^{\text {ns }}-0.48^{* *}$ \\
SUBM & $-0.02^{\text {ns }}$ & $0.04^{\text {ns }}$ & $-0.04^{\text {ns }}$ & $-0.01^{\text {ns }}$ & $-0.05^{\text {ns }} 0.25^{*}$ \\
SENS & $0.04^{\text {ns }}$ & $0.03^{\text {ns }}$ & $-0.45^{* *}$ & $0.16^{\text {ns }}$ & $0.04^{\text {ns }}-0.36^{* *}$ \\
TOLR & $-0.17^{\text {ns }}$ & $-0.06^{\text {ns }}$ & $-0.03^{\text {ns }}$ & $-0.02^{\text {ns }}$ & $0.00^{\text {ns }} 0.38^{* *}$ \\
TAXA & $0.32^{* *}$ & $0.53^{* *}$ & $-0.38^{* *}$ & $-0.33^{* *}$ & $0.34^{* *}-0.65^{* *}$ \\
\hline
\end{tabular}

${ }^{*} p<0.05$.

** $p<0.005$.

biotic integrity (MAXD, LITT, OVER, SENS, and TAXA) were negatively related to anthropogenic variables indicating increased human-induced stress. Likewise, metrics negatively related to biotic integrity (SUBM and TOLR) were positively related to anthropogenic variables indicating increased disturbance. Correlations of metrics with forested land use in the watershed were inversely related to metric correlations with other disturbance variables. The number of significant relationships between IBI metrics and anthropogenic variables also varied. SUBM exhibited only two significant correlations, whereas TAXA was significantly related with every anthropogenic variable.

An analysis of metric response to natural variables suggested co-variation with anthropogenic variables (Table 4b). However, correlations of metrics with natural variables were generally weaker and less numerous than correlations with anthropogenic variables, suggesting variation in response was more influenced by the latter. Five metrics were negatively correlated with temperature $(p<0.05)$, but SUBM and TOLR were positively correlated $(p<0.05)$. Four metrics were positively correlated with maximum lake depth $(p<0.05)$. Few metrics were correlated with lake sur-
Table 5

Coefficients and raw metric values used for scaling. $A=$ intercept, $B=$ slope, $M_{r}=$ raw metric, and $M_{s}=$ standardized metric.

\begin{tabular}{|c|c|c|c|c|}
\hline \multirow[t]{2}{*}{ Metrics } & \multicolumn{2}{|c|}{ Metric coefficients } & \multicolumn{2}{|c|}{$\begin{array}{l}\text { Values of raw } \\
\text { metrics }\left(M_{r}\right) \text { where }\end{array}$} \\
\hline & $A$ & $B$ & $M_{s}=0$ & $M_{s}=10$ \\
\hline MAXD & -1.06 & 0.61 & 1.75 & 18.20 \\
\hline LITT & 0 & 10.00 & 0 & 1.00 \\
\hline OVER & 0 & 0.82 & 0 & 12.20 \\
\hline SUBM $^{\mathrm{a}}$ & 11.50 & -19.39 & 1.00 & 0.50 \\
\hline SENS & 0 & 42.95 & 0 & 0.23 \\
\hline TOLR & 10.00 & -10.61 & 0.94 & 0 \\
\hline TAXA & -0.33 & 0.33 & 1.00 & 31.60 \\
\hline
\end{tabular}

a Coefficients represent values for transformed metric $(\lambda=6.04)$.

face area, alkalinity, percent littoral, and SDI. TAXA was the only metric that was significantly correlated with every natural variable $(p<0.005)$.

\subsection{IBI response}

Each metric was retained and standardized for calculation of IBI scores (Table 5). Mean IBI score for all lakes was 52.6 (range 18.7-80.1). Linear regression indicated that IBI scores were associated with several gradients of anthropogenic stress (Fig. 2). High IBI scores indicated lakes with low internal productivity and less anthropogenic stress originating in the watershed, whereas low IBI scores indicated lakes with high internal productivity and more anthropogenic stress originating in the watershed. IBI scores were negatively related to TSI $\left(R^{2}=0.57, F=130.3, \mathrm{df}=1,95, p<0.005\right)$, population density $\left(R^{2}=0.14, F=16.6, \mathrm{df}=1,95, p<0.005\right)$ and agricultural $\left(R^{2}=0.51, F=83.0, \mathrm{df}=1,79, p<0.005\right)$ and urban land use $\left(R^{2}=0.22, F=23.0, \mathrm{df}=1,79, p<0.005\right)$. IBI scores were positively related to forested land use $\left(R^{2}=0.51, F=84.7, \mathrm{df}=1,79, p<0.005\right)$. Results of linear regression comparisons of IBI scores with natural lake characteristics were also significant (Fig. 2). IBI scores were positively related to maximum lake depth $\left(R^{2}=0.19, F=22.8, \mathrm{df}=1\right.$, $95, p<0.005)$ and $\operatorname{SDI}\left(R^{2}=0.03, F=4.0, \mathrm{df}=1,94, p<0.05\right)$. IBI scores were negatively related to alkalinity $\left(R^{2}=0.08, F=6.0, \mathrm{df}=1,61\right.$, $p<0.05)$ and temperature $\left(R^{2}=0.46, F=82.9, \mathrm{df}=1,95, p<0.005\right)$. IBI scores were not related to surface or littoral area.

Principal component analysis indicated the relative influence of individual variables to cumulative variance among categories of variables used to develop MLR models (Table 6). Ant1 and Ant2 explained $79 \%$ of the total variance among anthropogenic variables. Nat1, Nat2, and Nat3 explained $75 \%$ of the total variance among natural variables. All1, All2, All3, and All4 explained $78 \%$ of the variance among all explanatory variables. More importantly, component axes illustrated many collinear relationships among

Table 6

Principal component axes and loadings describing anthropogenic, natural, and combined variables (all) used to develop multiple regression models for IBI scores. Cumulative variance (\%) explained by each category of component axes is shown below the axis title. TSI = Trophic state index (Carlson, 1977), SDI = shoreline development index (Wetzel, 2001).

\begin{tabular}{|c|c|c|c|c|c|c|c|c|c|}
\hline Variables & $\begin{array}{l}\text { Ant1 } \\
60\end{array}$ & $\begin{array}{l}\text { Ant2 } \\
79\end{array}$ & $\begin{array}{l}\text { Nat1 } \\
33\end{array}$ & $\begin{array}{l}\text { Nat2 } \\
55\end{array}$ & $\begin{array}{l}\text { Nat3 } \\
75\end{array}$ & $\begin{array}{l}\text { All1 } \\
38\end{array}$ & $\begin{array}{l}\text { All2 } \\
54\end{array}$ & $\begin{array}{l}\text { All3 } \\
67\end{array}$ & $\begin{array}{l}\text { All4 } \\
78\end{array}$ \\
\hline TSI & -0.39 & -0.47 & - & - & - & -0.34 & -0.12 & -0.33 & 0.13 \\
\hline People $/ \mathrm{km}^{2}$ & -0.39 & 0.52 & - & - & - & -0.34 & 0.22 & 0.25 & 0.34 \\
\hline $\mathrm{Ag}$ & -0.43 & -0.54 & - & - & - & -0.33 & -0.34 & -0.12 & -0.21 \\
\hline Urban & -0.45 & 0.46 & - & - & - & -0.35 & 0.00 & 0.25 & 0.26 \\
\hline Forest & 0.55 & 0.00 & - & - & - & 0.45 & 0.13 & -0.14 & 0.00 \\
\hline Area & - & - & -0.51 & 0.23 & 0.44 & 0.11 & -0.60 & 0.00 & 0.33 \\
\hline Maximum depth & - & - & -0.51 & 0.21 & -0.35 & 0.24 & -0.25 & 0.57 & 0.16 \\
\hline Alkalinity & - & - & 0.14 & 0.66 & 0.37 & -0.16 & -0.42 & 0.00 & -0.55 \\
\hline \% Littoral & - & - & 0.32 & -0.44 & 0.53 & -0.14 & 0.26 & -0.53 & 0.23 \\
\hline SDI & - & - & -0.47 & -0.21 & 0.50 & 0.19 & -0.35 & -0.29 & 0.52 \\
\hline Temperature & - & - & 0.37 & 0.48 & 0.15 & -0.43 & 0.00 & 0.19 & 0.00 \\
\hline
\end{tabular}



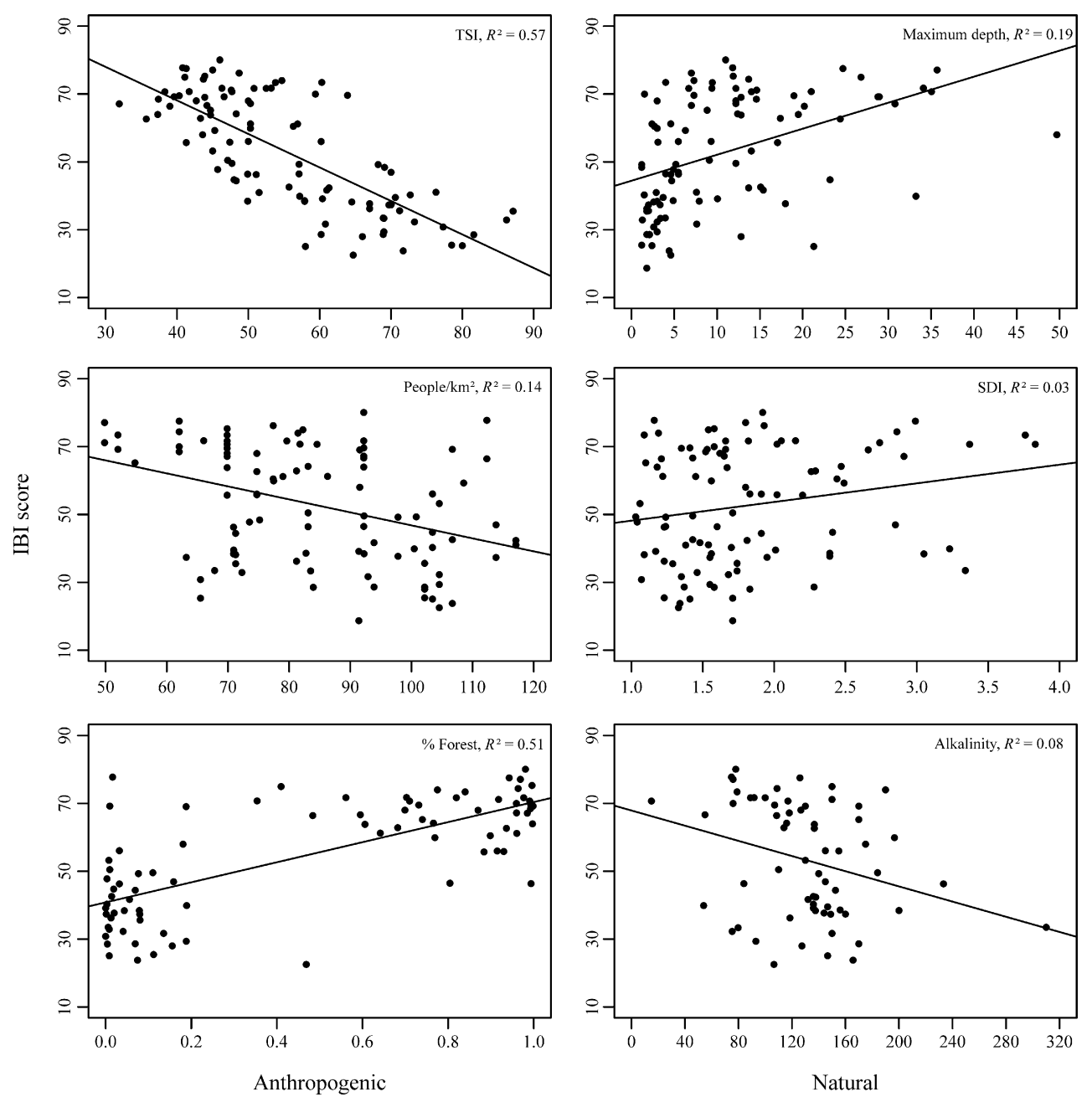

Fig. 2. IBI scores in relation to selected anthropogenic (left column) and natural variables (right column). Anthropogenic variables are trophic state index (TSI; Carlson, 1977), county population density (people $/ \mathrm{km}^{2}$ ), and \% forest land use. Natural variables are maximum lake depth (m), shoreline development index (SDI; Wetzel, 2001), and alkalinity $\left(\mathrm{mg} / \mathrm{L}, \mathrm{CaCO}_{3}\right)$. Least-squares regression lines are shown. Variables and coefficients of determination are shown in the top right corner of each graph. Variables are not transformed, except population density ( $p>0.05$ for non-transformed correlation, $\lambda=-0.48)$. IBI scores decreased $(p<0.005)$ with TSI, population density, and alkalinity, whereas IBI scores increased $(p<0.005)$ with \% forest land use, maximum depth, and SDI.

variables (Table 6) not accounted for in individual linear regression models. A comparison of $R^{2}$ values obtained from MLR models explained the relative contribution of variable categories to IBI response (Table 7) (Irz et al., 2008). The anthropogenic model indicated IBI scores were significantly correlated with both Ant1 and Ant 2 , which explained $72 \%$ of the variance in IBI scores $(p<0.005)$. The natural model indicated IBI scores were significantly correlated with Nat1, Nat2, and Nat3, which explained 33\% of the variance in IBI scores. The combined model indicated IBI scores were significantly correlated with only All1 and All2, which explained 67\% of the variance in IBI scores. The summation of $R^{2}$ values from the anthropogenic and natural models minus the $R^{2}$ value from the combined model was $38 \%$, indicating the separate MLR models individually explained the variation in IBI scores better than the combined model (Legendre and Legendre, 1998). Thus, IBI scores exhibited a unique response to human-induced stress independent of response to lake characteristics, although natural variables influenced the scores.

The NLF ecoregion had the highest mean IBI score (66.9; range 46.4-80.1), the NCHF ecoregion had a moderate mean IBI score (46.0; range 22.5-77.8), and the NGP/WCP ecoregion had the lowest mean IBI score (36.3; range 18.7-49.2). Mean IBI scores for each ecoregion (NCHF, NGP/WCP, NLF) were significantly different for at least two ecoregions $(F=48.3, \mathrm{df}=2,94, p<0.005)$. Tukey multiple
Table 7

Summary statistics for three multiple regression models describing IBI scores. Asterisks indicate significance of intercept and slope for variables within the model whereas $p$-value indicates significance of the entire model. $\alpha=0.05$; AIC $=$ Akaike's information criterion (Akaike, 1973).

\begin{tabular}{lccc}
\hline & \multicolumn{2}{l}{ Model } & \\
\cline { 2 - 4 } & Anthropogenic & Natural & Combined $^{\text {a }}$ \\
\hline Intercept & $54.49^{* *}$ & $53.01^{* *}$ & $54.01^{* *}$ \\
Ant1 & $7.68^{* *}$ & - & - \\
Ant2 & $5.08^{* *}$ & - & - \\
Nat1 & - & $-5.19^{* *}$ & - \\
Nat2 & - & $-4.78^{* *}$ & - \\
Nat3 & - & $-3.94^{*}$ & - \\
All1 & - & - & $6.52^{* *}$ \\
All2 & - & - & $2.87^{* *}$ \\
$R^{2}$ & 0.72 & 0.33 & 0.67 \\
$F$-Statistic & 107.7 & 11.0 & 40.2 \\
df & 2,78 & 3,58 & 3,54 \\
$p$-value & $<0.005$ & $<0.005$ & $<0.005$ \\
AIC & 353.0 & 329.9 & 267.9 \\
\hline
\end{tabular}

a Slopes for All3 and All4 were not significant.

${ }^{*} p<0.05$.

$p<0.005$. 


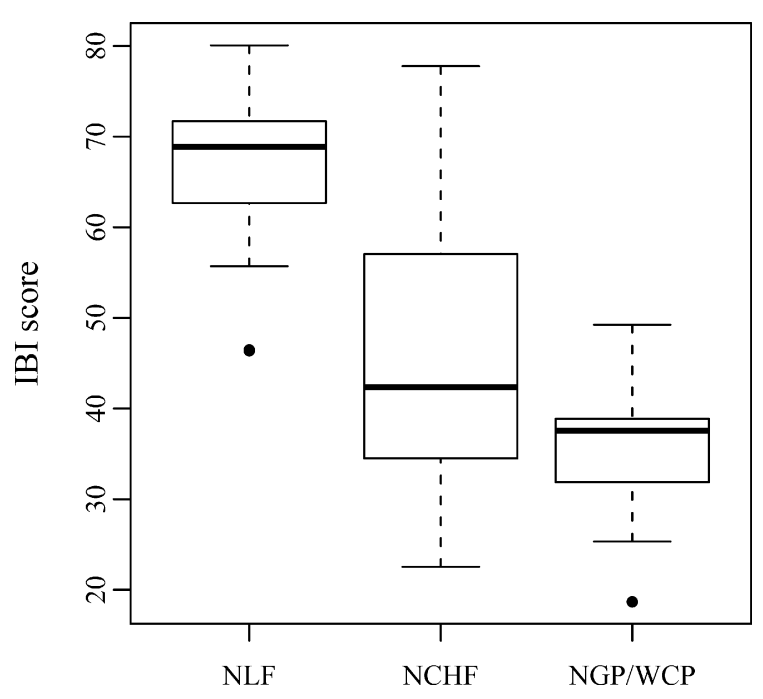

Fig. 3. Box-and-whisker plots of IBI scores for three ecoregions. Each box is bisected by the median and represents the interquartile range (IQR) for IBI scores (25-75th percentile). Outliers are present beyond whiskers $(1.5 \times \mathrm{IQR}) . \mathrm{NCHF}=$ North Central Hardwood Forests $(n=43)$, NGP/WCP $=$ Northern Glaciated Plains/Western Cornbelt Plains $(n=16)$, and NLF = Northern Lakes and Forests $(n=38)$.

comparisons indicated that IBI scores were significantly different between each ecoregion ( $p<0.05$ for all comparisons) (Fig. 3).

\subsection{IBI sensitivity and effects of sampling effort}

Metric sensitivity analyses suggested the relative contribution of each metric to IBI scores varied for all lakes and for each ecoregion (Table 8). Mean variance of IBI score differences for all lakes was 14.02. The variance of differences in IBI scores when SUBM was removed was the greatest (23.23), whereas the lowest variance was observed when OVER was removed (7.98). The median variance ratio for the NCHF ecoregion was 0.87 , indicating LITT, SUBM, and TOLR were potentially informative. The median variance ratio for the NGP/WCP ecoregion was 0.59, indicating LITT, SUBM, and TOLR were also potentially informative. The median variance ratio for the NLF ecoregion was 0.84, indicating MAXD, OVER, and SENS were potentially informative.

Sampling effort had a significant effect on IBI scores (Fig. 4). IBI scores for Christmas, Jane, and Square lakes at $90 \%$ effort were significantly greater than scores at $10 \%$ effort ( $p<0.005$ for all lakes). For each increase in effort, the greatest increase in IBI scores was between $10 \%$ and $20 \%$ effort (2.0\% mean increase in score for all lakes). Surprisingly, maximum IBI scores were not found at $100 \%$

\section{Table 8}

Sensitivity analysis of IBI response to metric removal. Ratios of variances for each ecoregion to total variance for all lakes are also shown. Metrics with variance ratios in bold italic are greater than the median ratio for all metrics in an ecoregion and are potentially informative. $\mathrm{NCHF}=$ North Central Hardwood Forests, NGP/WCP = Northern Glaciated Plains/Western Cornbelt Plains, and NLF = Northern Lakes and Forests.

\begin{tabular}{llllr}
\hline \multirow{2}{*}{ Metric } & \multicolumn{2}{l}{ Variance ratios } & \multirow{2}{*}{ Total variance } \\
\cline { 2 - 4 } & NCHF & NGP/WCP & NLF & \\
\hline MAXD & 0.73 & 0.48 & $\mathbf{1 . 2 0}$ & 16.88 \\
LITT & $\mathbf{0 . 9 9}$ & $\mathbf{2 . 5 8}$ & 0.31 & 12.17 \\
OVER & 0.87 & 0.27 & $\mathbf{1 . 3 6}$ & 7.98 \\
SUBM & $\mathbf{0 . 9 6}$ & $\mathbf{1 . 8 2}$ & 0.47 & 23.23 \\
SENS & 0.76 & 0.11 & $\mathbf{1 . 6 7}$ & 14.77 \\
TOLR & $\mathbf{1 . 1 7}$ & $\mathbf{0 . 5 9}$ & 0.31 & 13.87 \\
TAXA & 0.79 & 0.59 & 0.84 & 9.26 \\
\hline
\end{tabular}

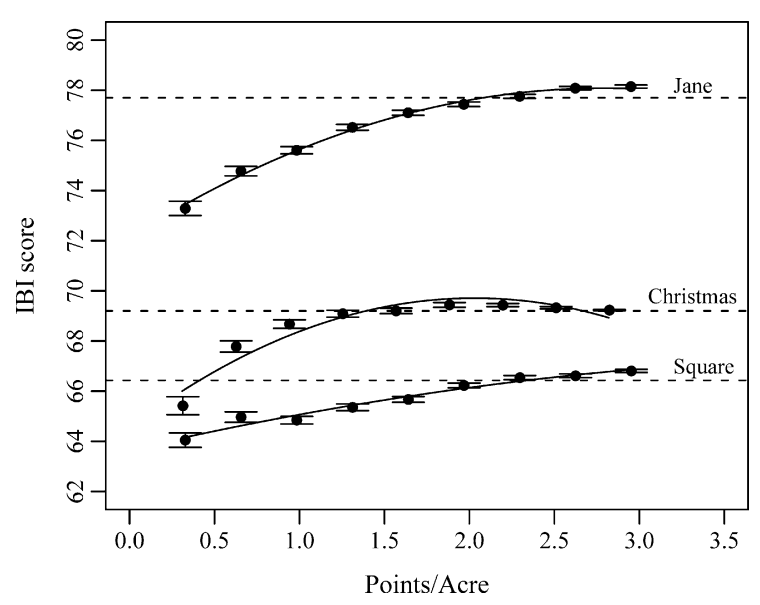

Fig. 4. IBI scores at varying levels of sampling effort for Christmas, Jane, and Square Lakes. Mean scores and 95\% confidence intervals for each lake are shown at $10 \%$ increments of sampling effort from $10 \%$ to $90 \%$. IBI scores at $100 \%$ sampling effort are indicated by dashed horizontal lines (Christmas $=69.20$; Jane $=77.70$; Square $=66.43$ ).

sampling effort. Jane and Square lakes indicated maximum scores at $90 \%$ effort, whereas Christmas Lake had a maximum score at $60 \%$ effort. Individual metric response to changes in sampling effort indicated that MAXD, SUBM, SENS, and TAXA generally increased continually with increased sampling effort, whereas OVER, LITT, and TOLR did not. Maximum values for the OVER metric were observed at $10 \%$ effort for Christmas, Jane, and Square lakes. Maximum values for LITT were observed at $10 \%$ effort for Christmas and Square lakes, and 40\% effort for Jane Lake. Maximum values for TOLR were observed at $80 \%$ effort for Christmas Lake, $50 \%$ effort for Jane Lake, and 40\% effort for Square Lake. Lastly, estimates of species richness with increased sampling effort generally exhibited an asymptotic relationship with richness at $100 \%$ effort (Fig. 5). Christmas, Jane, and Square lakes exhibited maximum increase in species richness estimates from $10 \%$ to $20 \%$ effort (17.3\% mean increase in estimates for all lakes), with estimates exhibiting diminished returns with additional effort.

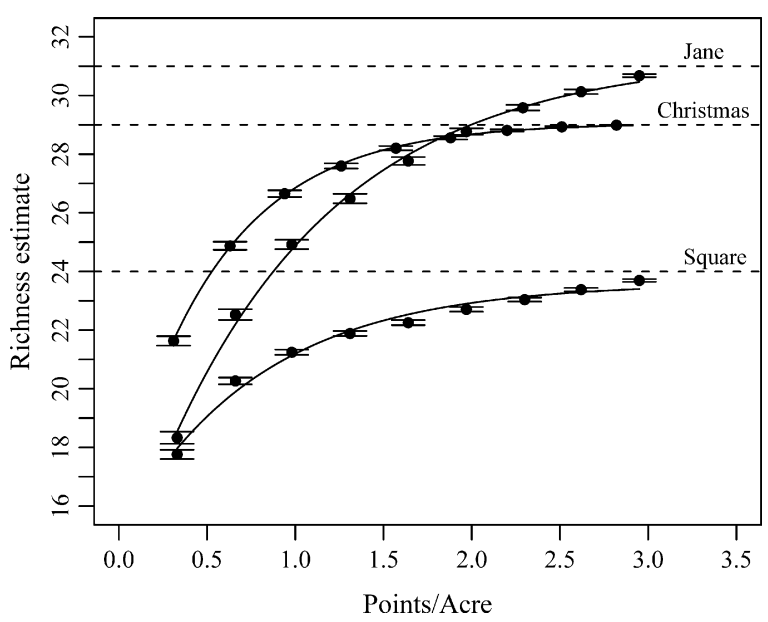

Fig. 5. Estimates of species richness at varying levels of sampling effort for Jane, Christmas, and Square Lakes. Mean richness estimates and 95\% confidence intervals for each lake are shown at 10\% intervals of sampling effort from $10 \%$ to $90 \%$. Species richness at $100 \%$ sampling effort is indicated by dashed horizontal lines $($ Christmas = 29; Jane = 31; Square $=24)$. 


\section{Discussion}

\subsection{Evaluation of the macrophyte IBI}

An IBI provides a biologically based multimetric index that integrates ecological, functional, and structural aspects of aquatic systems using metrics that reflect the quality of individual system components (Karr, 1981, 1991; Fausch et al., 1984). Within this context, the Minnesota macrophyte IBI integrates several components of lake aquatic plant communities into seven metrics adapted from the AMCI (Nichols et al., 2000) that respond predictably across a gradient of human-induced stress. Karr et al. (1986) presented several criteria to qualitatively evaluate the utility of IBIs for stream fish communities. These criteria have subsequently been used for development and validation of lake IBIs (Minns et al., 1994). The following provides a discussion of six index development and validation criteria applied to the Minnesota macrophyte IBI, with suggestions for further refinement and validation.

i) The index is biological. All seven metrics of the IBI are related to a structure or function of the macrophyte community. Therefore, the index addresses the biological integrity requirement of the CWA.

ii) Interpretable across many trophic levels or provides a connection to other organisms not directly involved in monitoring. Many biological indices utilize trophic-specialist metrics that emphasize response of specific biota to human-induced stress gradients. For example, macroinvertebrate communities exhibit a decline in abundance of trophic-specialist species (e.g., shredders, grazers, etc.) with increasing disturbance (Kerans and Karr, 1994). A disadvantage of macrophyte bioassessment is that aquatic plants represent primary production and are not directly interpretable across trophic levels. However, the macrophyte IBI could provide a connection to fish communities that are not an explicit component of the index. For example, the Minnesota fish-based IBI exhibits significant correlations with floristic quality of lake macrophyte communities (Drake and Valley, 2005). Furthermore, a preliminary comparison between the macrophyte IBI we developed and the Minnesota fish IBI illustrated that scores are highly correlated (Beck, 2009).

iii) Sensitive to ecosystem status. Significant correlations with landscape-level surrogates of environmental condition indicated that IBI scores and individual metrics are sensitive to watershed characteristics. Comparisons of indicator response with measures of human-induced stress are an important aspect of developing biological assessment methods that facilitate the identification of stressors affecting aquatic biota (Yoder and Rankin, 1998; Novotny et al., 2005). However, watershed characteristics and biological responses represent endpoints within a causal network hierarchy of stressor-impairment relationships (Novotny et al., 2005). The propagation of stress through multiple pathways and the specific response of biota is complicated and not fully understood because (1) response may co-vary with natural environmental characteristics, (2) response may not be linear, (3) multiple scale-dependent mechanisms may exist, and (4) a temporal disjunct between current and historical conditions may exist (Allan, 2004). As a result, it is inappropriate to identify distal stressors, such as urban or agricultural land use, as direct causation of low macrophyte IBI scores. Land use variables influence more proximal stressors, such as turbidity and excess nutrients, which have a direct impact on vegetation growth (Egertson et al., 2004). As such, the identification of stressors adjacent to biological endpoints would be necessary for problem remediation, as in the implementation of total maximum daily load (TMDL) programs mandated by the CWA.
The sensitivity of IBI scores to each metric varied among ecoregions. Additionally, a comparison of mean IBI scores among ecoregions suggested that study lakes were affected differently by disturbance gradients dependent on location, although it is unclear whether a complete disturbance gradient is represented within each region. Regardless, considering the applicability of specific metrics may be necessary for producing a regionally specific index that maximizes sensitivity to ecosystem characteristics. For example, the index was affected differently by species sensitive to anthropogenic stress depending on ecoregion. Sensitive taxa were found in only one lake in the NGP/WCP ecoregion group. As a result, IBI scores were not greatly affected by the SENS metric. Conversely, lakes within the NLF ecoregion were highly sensitive to changes of the SENS metric. NLF lakes also had consistently higher IBI scores than the NCHF and NGP/WCP ecoregions. For NGP/WCP lakes, the definition of sensitivity could be reconsidered (e.g., decrease $C$ value definition of sensitive) or regionally specific IBI thresholds for reference conditions could be developed. Alternatively, it is unclear if sensitive species defined for the IBI were historically present in the NGP/WCP ecoregion. Developing species-specific metrics for each ecoregion rather than a statewide application of relative frequency metrics may further improve discriminatory ability of the IBI.

iv) Responsive over its range to intended uses. Use of the IBI will be dependent on requirements of resources managers, which will likely necessitate an analysis of statewide applicability of the index. A quantitative analysis of IBI behavior within the range of the 44 lake types in Minnesota compared to those in the IBI development dataset will provide empirical information of index range of applicability. As such, the index should be evaluated in relation to an independently collected dataset not used for IBI development, which includes additional lake classes and ecoregions in Minnesota (Hughes et al., 1998; Drake and Valley, 2005).

Researchers outside of Minnesota interested in investigating use of the macrophyte IBI we have developed should consider several issues necessary for applying an index beyond the range of intended use. First, development of a multimetric index generally requires an extensive dataset (e.g., our IBI used 8 years of data). Biological datasets maintained by state and federal agencies as part of long-term monitoring programs could be used to facilitate index development. Second, characterization of biological communities for metric development requires regional understanding of aquatic ecology. For example, three metrics required the identification of sensitive, tolerant, and submersed species for regional adaption of the AMCI to Minnesota lakes (Sections 2.2 and 4.2). Although similar species are found in both states, species characteristics necessary for metric development may vary on a regional basis (Borman et al., 1997; Nichols et al., 2000). Third, cumulative index scores should be validated across disturbance gradients (Beck and Hatch, 2009). Although our analysis indicates the Minnesota macrophyte IBI is responsive to land use characteristics within a watershed, this may not apply in other regions. The response of biotic communities to anthropogenic impacts varies spatially and temporally (Simon, 2003). Identifying disturbance measures that regionally influence biotic communities and verifying the index reflects these impacts is necessary (Danz et al., 2007; Wang et al., 2008). Lastly, researchers should be familiar with the federal process for listing impaired waters (CWA sec. 305, 33USC1315). Although state governments have authority to develop bioassessment programs, the U.S. Environmental Protection Agency is given authority for approval of waters listed as impaired by each state. This process requires state agencies to develop numeric 
biological criteria that rely on index scores for the development of TMDL protocols (Gerritsen et al., 1998).

v) Reproducible and precise within the constraints of the data collection procedure. Sampling effort has commonly affected the development of lake IBIs, specifically the level of effort that maximizes the ratio of information and associated cost (Ferraro and Cole, 1992; Jennings et al., 1999; Whittier, 1999; Jones, 2008). Results of Monte Carlo simulations indicated a general increase in IBI scores with sampling effort. However, IBI scores were not maximized at $100 \%$ effort, unlike the relationship of species richness with sampling effort. An examination of the rarefaction curves (Gotelli and Colwell, 2001) helped explain IBI behavior as a function of effort. Several metrics exhibited relationships with sampling effort that were similar to species richness estimates (e.g., TAXA and SENS), whereas others did not (e.g., OVER, LITT and TOLR). Thus, the relationship of IBI scores with sampling effort is likely caused by complex interactions between metrics and is not completely explained by rarefaction curves (Gotelli and Colwell, 2001). Regardless, IBI scores did not change more than $5 \%$ with sampling effort, indicating that the index is relatively robust against changes in point density of surveys. As such, the sampling density of lakes used to develop the index likely provided a precise indication of IBI scores as related to effort.

Sampling method may also have a profound effect on reproducibility and precision of a biological index (Clarke et al., 2006a,b). Point intercept methods used to develop the Minnesota macrophyte IBI differed substantially from qualitative methods used to develop the PIBI (Rothrock et al., 2008). The point intercept method has been described as a rapid sampling design that provides quantitative information about the spatial distribution of macrophyte communities (Madsen, 1999). Advantages offered by the point intercept method or methods used to develop the PIBI are unclear, although both provide sufficient information for calculating respective index scores. A comparison of each method could indicate the practicality of each approach as applied to the IBI. Previous analyses have suggested that point intercept methods can provide maximum benefit per unit of cost (Mikulyuk et al., in press), although the benefits have not been specifically examined in relation to the IBI.

vi) Variability of the measure should be low. IBI variability can originate from sampling, anthropogenic, or natural variability (Karr et al., 1986). Sampling variability was examined using sampling point density as a proxy in Monte Carlo simulations. However, the precision of IBI scores across different sampling dates is unclear and should be examined. Regardless, the IBI is likely minimally affected by sample date because the original AMCI did not exhibit substantial seasonal variability of scores (Nichols et al., 2000).

An empirical interpretation of the effects of anthropogenic and natural variability on metrics and IBI scores was conducted using correlation, individual linear regression models, and methods adapted from Legendre and Legendre (1998) and Irz et al. (2008). The ability of an index to accurately reflect anthropogenic variation among sites is reliant upon the ability of each constituent metric to account for natural variability (Smogor and Angermeier, 2001). Individual linear regression results suggested that maximum lake depth, alkalinity, SDI, and temperature have a significant effect on IBI scores. However, variable loadings within each principal component axis indicated natural variables were highly correlated and confounded with anthropogenic disturbance variables, such as TSI and agricultural land use. The use of principal component axes to develop multiple regression models provided an examination of collinearity among explanatory variables.
Although our analysis suggested a unique response of the IBI to anthropogenic variables, methods for metric normalization to account for natural variability (Fausch et al., 1984; Schulz et al., 1999; Smogor and Angermeier, 1999; Norton et al., 2000) may produce an IBI that maximizes signal-to-noise response ratios and minimizes undesirable variability. Methods to account for species-area relationships (MacArthur and Wilson, 1967) are commonly used to normalize IBI metrics by stream order (Fausch et al., 1984) or lake surface area (Schulz et al., 1999). Normalizing metrics by natural variables that exhibited the strongest correlations with overall index scores could improve discriminatory ability of a Minnesota macrophyte IBI.

An alternative approach for reducing index variability attributed to natural characteristics is to adopt regionally specific reference conditions. As such, many studies have focused on the development and application of an IBI for a specific ecoregion (Miller et al., 1988; Gerritsen et al., 1998; Beck and Hatch, 2009). Although useful for eventual implementation of an index, developing a regionally specific IBI was not an objective of this study. Our approach differed in that metrics and IBI scores were examined on a statewide basis, prior to investigating metric and index behavior in individual ecoregions. The intent was to identify information relevant for further index development and validation, rather than propose a final IBI. For example, statewide regression analyses considering all lakes in the dataset indicated a need to control for lake depth to improve discriminatory ability of the IBI. An analysis of index response limited to ecoregions may have prevented the identification of this information as many gradients, such as lake depth, are not as pronounced on a regional basis (Moyle, 1945, 1956). Further work developing the Minnesota macrophyte IBI will likely be facilitated by the information obtained from statewide analyses.

\subsection{Comparison with the $\mathrm{AMCI}$}

Several important similarities and differences between the Minnesota macrophyte IBI and the AMCI should be identified. Both IBIs exhibit significant relationships with measures of human-induced stress, which suggests they are robust indicators of lake quality for respective regions in Wisconsin and Minnesota. The primary difference between the macrophyte IBI and the AMCI was the use of an empirical approach to ensure each metric of the Minnesota IBI was appropriate for index development and to examine properties of the IBI (described in Sections 2.4, 2.5 and 2.6). Regional and scaling modifications of the AMCI were also considered necessary for IBI development in Minnesota. The remainder of this subsection describes the rationale for the modifications of the AMCI used to develop the Minnesota macrophyte IBI.

Nichols et al. (2000) suggested that potentially different sensitive and exotic species should be identified for regional adaptation of the AMCI outside of Wisconsin. As such, careful consideration of species for relative frequency metrics provided an adequate approach for regional adaptation to Minnesota. Additionally, the definition of sensitivity may affect discriminatory ability of an index, particularly for aquatic plants that integrate several environmental characteristics (Lacoul and Freedman, 2006). $C$ values used in this study were determined by professional judgment and considered species substrate preference, turbidity tolerance, rooting strength, primary reproductive means, and tolerance to water drawdown (Nichols, 1999; Milburn et al., 2007). Despite a degree of subjectivity, $C$ values were assumed to provide accurate indications of sensitivity. Comparisons between floristic quality assessments using $C$ values and those using empirically derived indications of tolerance have found that comparable results are obtained with both measures (Mushet et al., 2002). 
Nichols et al. (2000) further suggested that metric scaling for calculating IBI scores is a subjective process open to interpretation. Indeed, the relationship of a metric, and by extension IBI scores, to human-induced stress is largely dependent on the assumptions used to scale metrics (Smogor and Angermeier, 1999). For example, the SUBM metric of the original AMCI was scaled such that raw values between $75 \%$ and $85 \%$ were considered ideal for water quality and received a 10 , with scores decreasing above and below these values. Although the subjective scaling used to develop the AMCI produced a discriminatory index, scaling describing maximum or minimum thresholds was not used to develop Minnesota IBI metrics.

The direction of metric scaling used for the Minnesota IBI was determined a posteriori with correlation coefficients of metric values and anthropogenic variables, unlike methods used for the AMCI. Correlation coefficients indicated that all metrics of the Minnesota IBI responded similarly to human-induced stress as AMCI metrics, with the exception of the SUBM metric which exhibited a positive relationship with stress. The SUBM metric in our study was correlated with the TOLR metric $(\rho=0.32, \mathrm{df}=95, p<0.005)$, suggesting that lakes with lower biotic integrity have increased submersed species with greater tolerances for stress. Lakes with low IBI scores often had low species richness and extremely dense beds of invasive or highly tolerant submersed species such as Eurasian milfoil (Myriophyllum spicatum), curly-leaf pondweed (Potamogeton crispus), or coontail (Ceratophyllum demersum).

A comparison of the AMCI and Minnesota macrophyte IBI illustrates the use of alternative methods for index development. Discussions of differing methods and appropriate uses are prevalent in the literature (e.g., Karr, 1991; Gerritsen et al., 1998). Lack of consensus and little standardization of methods for index development has resulted in a proliferation of IBIs and rapid bioassessment protocols in the United States that are limited to specific geographic regions or habitats (Plafkin et al., 1989; Beck and Hatch, 2009). The development of regionally based indices has likely been caused by two reasons. First, the influence of natural variability on index response can be minimized by controlling factors that naturally affect composition of biotic communities, e.g., developing indices for lakes with similar geophysical and chemical characteristics (Drake and Pereira, 2002). This limitation imposes constraints on the types of systems for which an index may be applicable. Second, institutional and social constraints may limit the use of indices that are ecologically valid across political boundaries (Hughes et al., 2000; Moog and Chovanec, 2000). These two issues suggest that indices applicable on a larger scale should be developed as a more efficient means to fulfill requirements of the CWA. Whittier et al. (2007) illustrated an approach for the development of large-scale IBIs to assess the condition of streams and rivers in 12 western U.S. states. The approach is useful if large consistently collected databases are available (e.g., coordinated state and federal efforts), reference sites are distributed across a wide range of system types and sizes, an index is calibrated for natural characteristics, and an efficient process is used for selecting candidate metrics. Careful consideration of these factors could enable the development of large-scale IBIs and prevent inconsistencies that promote proliferation of regionally based indices. Through state and federal cooperation between natural resource agencies, the Minnesota macrophyte IBI could be combined with similar indices for use on a larger geographic range.

\subsection{Conclusions}

The Minnesota macrophyte IBI provides an approach for bioassessment that enables the identification of unique information about environmental condition. The IBI also provides resource managers with a framework for fulfilling the biological integrity requirement of the CWA. Understanding the intricacies of accurate bioassessment will improve the initial index developed in this study and produce a tool for understanding land use and climate change impacts on lacustrine environments in both Minnesota and other regions of the midwest United States.

\section{Role of funding source}

Funding was provided by the Minnesota Department of Natural Resources using Clean Water Legacy funds appropriated by the Minnesota Legislature. All data were obtained from the Minnesota Department of Natural Resources. Study design, data analyses, and interpretations were developed and conducted solely by the authors. Mention of trade names or commercial products does not imply endorsement by the U.S. Government.

\section{Acknowledgements}

The authors wish to thank Dr. David Wright of the Minnesota Department of Natural Resources for general project assistance. We also thank Melissa Drake, Cynthia Tomcko, Heidi Langrehr, and two anonymous reviewers for providing critical feedback during manuscript preparation. Lastly, we thank Wendy Crowell, Nicole Hansel-Welch, Donna Perleberg, and Nicholas Proulx for providing data.

\section{References}

Akaike, H., 1973. Information theory and an extension of the maximum likelihood principle. In: Petrov, B.N., Csaki, F. (Eds.), Second International Symposium on Information Theory. Akademiai Kiado, Budapest, pp. 268-281.

Allan, J.D., 2004. Landscapes and riverscapes: the influence of land use on stream ecosystems. Annu. Rev. Ecol. Evol. Syst. 35, 257-284.

Beck, M.W., 2009. Development of an ecological assessment method for Minnesota lakes. Thesis, University of Minnesota, St. Paul, MN.

Beck, M.W., Hatch, L.K., 2009. A review of research on the development of lake indices of biotic integrity. Environ. Rev. 17, 21-44.

Blocksom, K.A., Kurtenbach, J.P., Klemm, D.J., Fulk, F.A., Cormier, S.M., 2002. Development and evaluation of the Lake Macroinvertebrate Integrity Index (LMII) for New Jersey lakes and reservoirs. Environ. Monit. Assess. 77, 311-333.

Borman, S.C., Korth, R., Temte, J., 1997. Through the Looking Glass: A Field Guide to Aquatic Plants. Reindl Printing, Inc., Merrill, WI.

Burrough, P.A., McDonnell, R.A., 1998. Principles of Geographical Information Systems, 2nd ed. Oxford University Press, New York, NY.

Carlson, R.E., 1977. Trophic state index for lakes. Limnol. Oceanogr. 22, 361-369.

Cheruvelil, K.S., Soranno, P.A., 2008. Relationships between lake macrophyte cover and lake and landscape features. Aquat. Bot. 88, 219-227.

Clarke, R.T., Davy-Bowker, J., Sandin, L., Friberg, N., Johnson, R.K., Bis, B., 2006a. Estimates and comparisons of the effects of sampling variation using 'national' macroinvertebrate sampling protocols on the precision of metrics used to assess ecological status. Hydrobiologia 566, 477-503.

Clarke, R.T., Lorenz, A., Sandin, L., Schmidt-Kloiber, A., Strackbein, J., Kneebone, N.T., Haase, P., 2006b. Effects of sampling and sub-sampling variation using the STAR-AQEM sampling protocol on the precision of macroinvertebrate metrics. Hydrobiologia 566, 441-459.

Clayton, J., Edwards, T., 2006. Aquatic plants as environmental indicators of ecological condition in New Zealand lakes. Hydrobiologia 570, 147-151.

Cook, R.D., Weisberg, S., 1999. Applied Regression Including Computing and Graphics. Wiley, New York, NY.

Cross, T., McInerny, M., 2006. Relationships between aquatic plant cover and fish populations based on Minnesota lake survey data. Investigational Report 537, Fisheries and Wildlife Division, Minnesota Department of Natural Resources, Hutchinson, Minnesota.

Danz, N.P., Niemi, G.J., Regal, R.R., Hollenhorst, T., Johnson, L.B., Hanowski, J.M., Axler, R.P., Ciborowski, J.J.H., Hrabik, T., Brady, V.J., Kelly, J.R., Morrice, J.A., Brazner, J.C., Howe, R.W., Johnston, C.A., Host, G.E., 2007. Integrated measures of anthropogenic stress in the US Great Lakes basin. Environ. Manage. 39, 631-647.

Drake, M.T., Pereira, D.L., 2002. Development of a fish-based index of biotic integrity for small inland lakes in central Minnesota. N. Am. J. Fish. Manage. 22, 1105-1123.

Drake, M.T., Valley, R.D., 2005. Validation and application of a fish-based index of biotic integrity for small central Minnesota lakes. N. Am. J. Fish. Manage. 25, 1095-1111.

Egertson, C.J., Kopaska, J.A., Downing, J.A., 2004. A century of change in macrophyte abundance and composition in response to agricultural eutrophication. Hydrobiologia 524, 145-156. 
ESRI (Environmental Systems Research Institute), 2006. ArcGIS. 9.2. ESRI, Redlands, California.

Fausch, K.D., Karr, J.R., Yant, P.R., 1984. Regional application of an index of biotic integrity based on stream fish communities. Trans. Am. Fish. Soc. 113, 39-55.

Ferraro, S.P., Cole, F.A., 1992. Taxonomic level sufficient for assessing a moderate impact on macrobenthic communities in Puget Sound, Washington, USA. Can. J. Fish. Aquat. Sci. 49, 1184-1188.

Fore, L.S., Karr, J.R., Conquest, L.L., 1994. Statistical properties of an index of biological integrity used to evaluate water resources. Can. J. Fish. Aquat. Sci. 51, 1077-1087.

Genkai-Cato, M., Carpenter, S.R., 2005. Eutrophication due to phosphorus recycling in relation to lake morphometry, temperature, and macrophytes. Ecology 86, 210-219.

Gerritsen, J., Carlson, R.E., Dycus, D.L., Faulkner, C., Gibson, G.R., Harcum, J., Markowitz, S.A., 1998. Lake and reservoir bioassessment and biocriteria. Technical Guidance Document, EPA-841-B-98-007, Office of Water, US Environmental Protection Agency, Washington, DC.

Gotelli, N.J., Colwell, R.K., 2001. Quantifying biodiversity: procedures and pitfalls in the measurement and comparison of species richness. Ecol. Lett. 4, 379-391.

Hughes, R.M., Kaufmann, P.R., Herlihy, A.T., Kincaid, T.M., Reynolds, L., Larsen, D.P., 1998. A process for developing and evaluating indices of fish assemblage integrity. Can. J. Fish. Aquat. Sci. 55, 1618-1631.

Hughes, R.M., Paulsen, S.G., Stoddard, J.L., 2000. EMAP-surface waters: a multiassemblage, probability survey of ecological integrity in the USA. Hydrobiologia 422, 429-443.

Irz, P., De Bortoli, J., Michonneau, F., Whittier, T.R., Oberdorff, T., Argillier, C., 2008. Controlling for natural variability in assessing the response of fish metrics to human pressures for lakes in north-east USA. Aquat. Conserv. Mar. Freshw. Ecosyst. 18, 633-646.

Jennings, M.J., Lyons, J., Emmons, E.E., Hatzenbeler, G.R., Bozek, M., Simonson, T.D., Beard Jr., T.D., Fago, D., 1999. Toward the development of an index of biotic integrity for inland lakes in Wisconsin. In: Simon, T.P. (Ed.), Assessing the Sustainability and Biological Integrity of Water Resources Using Fish Communities. CRC Press, Boca Raton, FL, pp. 541-562.

Jones, F.C., 2008. Taxonomic sufficiency: the influence of taxonomic resolution on freshwater bioassessments using benthic macroinvertebrates. Environ. Rev. 16, $45-69$.

Jurik, T.W., Wang, S.C., Vandervalk, A.G., 1994. Effects of sediment load on seedling emergence from wetland seed banks. Wetlands 14, 159-165.

Kane, D.D., Gordon, S.I., Munawar, M., Charlton, M.N., Culver, D.A., 2009. The Planktonic Index of Biotic Integrity (P-IBI): an approach for assessing lake ecosystem health. Ecol. Ind. 9, 1234-1247.

Karr, J.R., Fausch, K.D., Angermier, P.L., Yant, P.R., Schlosser, I.J., 1986. Assessing Biological Integrity in Running Waters: A Method and its Rationale. Illinois Natural History Survey, Illinois, p. 31 (Special Publication 5).

Karr, J.R., 1981. Assessment of biotic integrity using fish communities. Fisheries 6 , 21-27.

Karr, J.R., 1991. Biological integrity: a long-neglected aspect of water resource management. Ecol. Appl. 1, 66-84.

Kerans, B.L., Karr, J.R., 1994. A benthic index of biotic integrity (B-Ibi) for rivers of the Tennessee Valley. Ecol. Appl. 4, 768-785.

Lacoul, P., Freedman, B., 2006. Environmental influences on aquatic plants in freshwater ecosystems. Environ. Rev. 14, 89-136.

Legendre, P., Legendre, L., 1998. Numerical Ecology, 2nd ed. Elsevier, Amsterdam.

Lewis, P.A., Klemm, D.J., Thoeny, W.T., 2001. Perspectives on use of a multimetric lake bioassessment integrity index using benthic macroinvertebrates. Northeast. Nat. 8, 233-246.

MacArthur, R.H., Wilson, E.O., 1967. The Theory of Island Biogeography. Princeton University Press, Princeton, NJ.

Madsen, J.D., 1999. Point intercept and line intercept methods for aquatic plant management. TN APCRP-M1-02, APCRP Technical Notes Collection, U.S. Army Engineer Center, Vicksburg, Mississippi.

McCune, B., Grace, J.B., 2002. Analysis of Ecological Communities. MjM Software Design, Gleneden Beach, OR.

McDonough, T.A., Hickman, G.D., 1999. Reservoir fish assemblage index development: a tool for assessing ecological health in Tennessee Valley Authority impoundments. In: Simon, T.P. (Ed.), Assessing the Sustainability and Biological Integrity of Water Resources Using Fish Communities. CRC Press, Boca Raton, FL, pp. 523-540.

Mikulyuk, A., Hauxwell, J., Rasmussen, P., Knight, S., Wagner, K.I., Nault, M.E., Ridgely, D., in press. Testing a methodology for assessing plant communities in temperate inland lakes. Lake Reserv. Manage.

Milburn, S.A., Bourdaghs, M., Husveth, J.J., 2007. Floristic Quality Assessment for Minnesota Wetlands: wq-bwm2-01. Minnesota Pollution Control Agency, St. Paul, MN.

Miller, D.L., Leonard, P.M., Hughes, R.M., Karr, J.R., Moyle, P.B., Schrader, L.H., Thompson, B.A., Daniels, R.A., Fausch, K.D., Fitzhugh, G.A., Gammon, J.R., Halliwell, D.B. Angermeier, P.L., Orth, D.J., 1988. Regional applications of an index of biotic integrity for use in water-resource management. Fisheries 13, 12-20.

Minns, C.K., Cairns, V.W., Randall, R.G., Moore, J.E., 1994. An index of biotic integrity (IBI) for fish assemblages in the littoral zone of Great Lakes' areas of concern. Can. J. Fish. Aquat. Sci. 51, 1804-1822.

MNDNR (Minnesota Department of Natural Resources), 2009. The DNR Data Deli. MNDNR (Minnesota Department of Natural Resources), St. Paul, MN, accessed 2009, http://deli.dnr.state.mn.us/.
MNDOA(Minnesota Department of Administration), 2000. 2000 Census SF1 and SF2: Report and Mapping Menu. MNDOA (Minnesota Department of Administration), St. Paul, MN, accessed 2009, http://www.lmic.state.mn.us/datanetweb/php/ census2000/c2000.html.

MNCPA (Minnesota Pollution Control Agency), 2009. Environmental Data Access-Water Quality Data. MNPCA (Minnesota Pollution Control Agency), St. Paul, MN, accessed 2009, http://www.pca.state.mn.us//data/edaWater/ index.cfm.

Moog, O., Chovanec, A., 2000. Assessing the ecological integrity of rivers: walking the line among ecological, political and administrative interests. Hydrobiologia 422, 99-109.

Moyle,J.B., 1945. Some chemical factors influencing the distribution of aquatic plants in Minnesota. Am. Midl. Nat. 34, 402-420.

Moyle, J.B., 1956. Relationships between the chemistry of Minnesota surface waters and wildlife management. J. Wildl. Manage. 20, 303-320.

Mushet, D.M., Euliss, N.H., Shaffer, T.L., 2002. Floristic quality assessment of one natural and three restored wetland complexes in North Dakota, USA. Wetlands $22,126-138$.

Nichols, S., 1999. Floristic quality assessment of Wisconsin lake plant communities with example applications. Lake Reserv. Manage. 15, 133-141.

Nichols, S., Weber, S., Shaw, B., 2000. A proposed aquatic plant community biotic index for Wisconsin lakes. Environ. Manage. 26, 491-502.

Norton, S.B., Cormier, S.M., Smith, M., Jones, R.C., 2000. Can biological assessments discriminate among types of stress? A case study from the Eastern Corn Belt Plains ecoregion. Environ. Toxicol. Chem. 19, 1113-1119.

Novotny, V., Bartosova, A., O'Reilly, N., Ehlinger, T., 2005. Unlocking the relationship of biotic integrity of impaired waters to anthropogenic stresses. Water Res. 39, 184-198.

Omernik, J.M., 1987. Ecoregions of the conterminous United States. Ann. Assoc. Am. Geogr. 77, 118-125.

Plafkin, J.L., Barbour, M.T., Porter, K.D., Gross, S.K., Hughes, R.M., 1989. Rapid Bioassessment Protocols for Use in Streams and Rivers: Benthic Macroinvertebrates and Fish. US Environmental Protection Agency, Washington, DC.

RDCT (R. Development Core Team), 2009. R: A Language and Environment for Statistical Computing. Version 2.9.0. R Foundation for Statistical Computing, Vienna, Austria, ISBN 3-900051-07-0, http://www.R-project.org.

Roth, N.E., Allan, J.D., Erickson, D.L., 1996. Landscape influences on stream biotic integrity assessed at multiple spatial scales. Landscape Ecol. 11, 141156.

Rothrock, P.E., Simon, T.P., Stewart, P.M., 2008. Development, calibration, and validation of a littoral zone plant index of biotic integrity (PIBI) for lacustrine wetlands. Ecol. Ind. 8, 79-88.

Scheffer, M., Carpenter, S., Foley, J.A., Folke, C., Walker, B., 1998. Catastrophic shifts in ecosystems. Nature 413, 591-596.

Schulz, E.J., Hoyer, M.V., Canfield, D.E., 1999. An index of biotic integrity: a test with limnological and fish data from sixty Florida lakes. Trans. Am. Fish. Soc. 128, 564-577.

Schupp, D.H., 1992. An ecological classification of Minnesota lakes with associated fish communities. Investigational Report 41, Section of Fisheries, Minnesota Department of Natural Resources, St. Paul, Minnesota.

Simon, T.P. (Ed.), 2003. Biological Response Signatures: Indicator Patterns Using Aquatic Communities. CRC Press, Boca Raton, FL.

Smogor, R.A., Angermeier, P.L., 1999. Relations between fish metrics and measures of anthropogenic disturbance in three IBI regions in Virginia. In: Simon, T.P. (Ed.), Assessing the Sustainability and Biological Integrity of Water Resources Using Fish Communities. CRC Press, Boca Raton, FL, pp. 585-610.

Smogor, R.A., Angermeier, P.L., 2001. Determining a regional framework for assessing biotic integrity of Virginia streams. Trans. Am. Fish. Soc. 130, 18-35.

Thoma, R.F., 1999. Biological monitoring and an index of biotic integrity for Lake Erie's nearshore waters. In: Simon, T.P. (Ed.), Assessing the Sustainability and Biological Integrity of Water Resources Using Fish Communities. CRC Press, Boca Raton, FL, pp. 417-461.

USGS (United States Geological Survey), 2009. Multi-Resolution Land Characteristics Consortium. Reston, Virginia, accessed 2009. http://www.mrlc.gov/.

Valley, R.D., Drake, M.T., 2007. What does resilience of a clear-water state in lakes mean for the spatial heterogeneity of submersed macrophyte biovolume? Aquat. Bot. 87, 307-319.

Wang, L., Brenden, T., Seelbach, P., Cooper, A., Allan, D., Clark Jr., P., Wiley, M., 2008. Landscape based identification of human disturbance gradients and reference conditions for Michigan streams. Environ. Monit. Assess. 141, 1-17.

Wetzel, R.G., 2001. Limnology: Lake and River Ecosystems. Academic Press, San Diego, CA.

Whittier, T.R., 1999. Development of IBI metrics for lakes in southern New England. In: Simon, T.P. (Ed.), Assessing the Sustainability and Biological Integrity of Water Resources Using Fish Communities. CRC Press, Boca Raton, FL, pp. 563-582.

Whittier, T.R., Hughes, R.M., Stoddard, J.L., Lomnicky, G.A., Peck, D.V., Herlihy, A.T., 2007. A structured approach for developing indices of biotic integrity: three examples from streams and rivers in the western USA. Trans. Am. Fish. Soc. 136 718-735.

Yoder, C.O., Rankin, E.T., 1998. The role of biological indicators in a state water quality management process. Environ. Monit. Assess. 51, 61-88. 